\title{
Intracellular Second Messenger
}

National Cancer Institute

\section{Source}

National Cancer Institute. Intracellular Second Messenger. NCI Thesaurus. Code C1903.

A non-proteinaceous signaling molecule that is generated by intracellular enzymes that respond to the binding of extracellular ligands to cell surface receptors. These compounds serve as intermediate signals for a diverse set of cellular processes. 